\title{
Stool Antigen Examination as a Diagnostic Tool for Dyspeptic Patient caused by Helicobacter pylori Infection: A Case-based Literature Review
}

\author{
Haifa Mayang Lestari ${ }^{1}$, Jatmiko Gustinanda ${ }^{1}$ (D), Nadzila Anindya Tejaputri ${ }^{1}$, Nur Afiahuddin Tumpu ${ }^{1}$, Taris Radifan $^{1}$, Melva Louisa ${ }^{2 *}$ \\ ${ }^{1}$ Undergraduate Medical Program, Faculty of Medicine, Universitas Indonesia, Jakarta, Indonesia; ${ }^{2}$ Department of Pharmacology \\ and Therapeutics, Faculty of Medicine, Universitas Indonesia, Jakarta, Indonesia
}

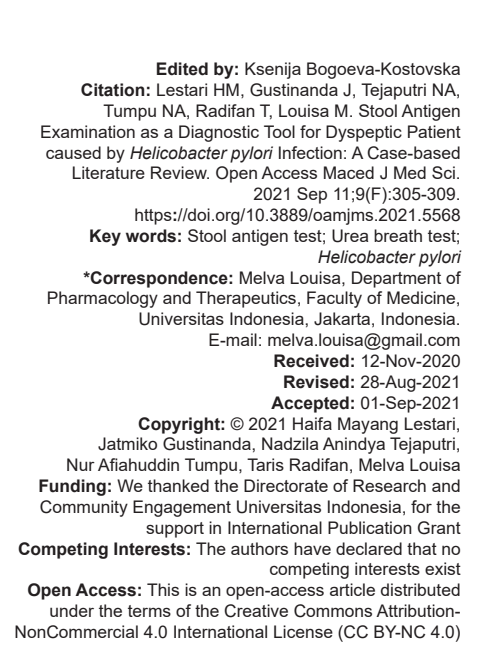

\begin{abstract}
Today, the gold standard for diagnosing Helicobacter pylori infection is by urea breath test (UBT). However, UBT tests are not widely available in several remote areas in Indonesia. Stool antigen test (SAT) is an alternative diagnostic test for $\mathrm{H}$. pylori infection. However, it is unclear whether the performance of SAT to diagnose $\mathrm{H}$. pylori infection can be comparable with UBT accuracy. This report was aimed to determine the accuracy of SAT to diagnose $H$. pylori infection as an alternative to UBT. Our case-based literature review indicates that SAT has high sensitivity (79-96.4\%); therefore, SAT can help doctors in ruling out $\mathrm{H}$. pylori infection. SAT also demonstrates remarkable specificity of stool antigen examination $(98.6-100 \%)$, suggesting that SAT can help doctors in ruling in $\mathrm{H}$. pylor infection.
\end{abstract}

\section{Introduction}

Dyspepsia is a complex symptom that arises in the upper gastrointestinal tract. The symptoms include epigastric pain or discomfort, heartburn, excessive burping, excessive belching, acid regurgitation, slow digestion, nausea, bloating, and early satiety. The etiology of dyspepsia consists of acid secretion such as a duodenal ulcer or gastroesophageal reflux disease, impaired gastrointestinal motility, functional, hypersensitivity, neuromuscular dysfunction, and specific stimuli in example caused by Helicobacter pylori [1]. H. pylori infection is very common in the world. Several studies for Asia's $H$. pylori infection prevalence rates ranging from $20 \%$ to $84 \%$, Africa's prevalence rates $41.3 \% 91.3 \%$, and USA's prevalence rates among the low-income population is about 79\% [2], [3], [4], [5], [6], [7], [8], [9]. In Indonesia, $H$. pylori infection prevalence is $22.1 \%$ [10]. Today, the gold standard to diagnose $H$. pylori infection is by urea breath test (UBT) [11].

$H$. pylori produce active urease that converts urease to ammonium and converts $\mathrm{CO}_{2}$ in the stomach.
UBT uses isotope-labeled urea consumed by the patient that will be broken down by $H$. pylori. UBT is divided into two types, ${ }^{13} \mathrm{C}$, and ${ }^{14 \mathrm{C}}$ tests. The ${ }^{13} \mathrm{C}$ is nonradioactive, while ${ }^{14} \mathrm{C}$ uses radioactive isotope. UBT's function is to confirm the colonization and to monitor $H$. pylori's eradication [12]. In Indonesia, UBT is not widely available. The ${ }^{13} \mathrm{C}$-UBT is available in cities such as Jakarta, Surabaya, Medan, and Makasar, meanwhile ${ }^{14} \mathrm{C}$ available in North Sumatra, West Java, Jakarta, Yogyakarta, East Java, Bali. UBT is relatively expensive [13].

Stool antigen test (SAT) is an alternative diagnostic test for $H$. pylori infection. SAT has several advantages, such as non-invasive, more accessible, faster, and does not require expensive chemicals and equipment. Hence, the price is less costly than UBT (the cost is about USD 20). Also, the SAT is widely used in Indonesia. The first method of SAT is the enzyme immunoassay (EIA), which is a method based on polyclonal antibodies and has been shown to have high accuracy. EIA-based assays, such as the commercial kit Premier Platinum HpSA, can be used in Indonesia [6], [7]. Although it is well known that the SAT has high accuracy, 
it is not clear whether the performance of the SAT to diagnose $H$. pylori infection can be comparable with UBT accuracy. Therefore, this case-based review will discuss the comparison of the accuracy of SAT and UBT in diagnosing $H$. pylori infection.

\section{Case Presentation}

A 40-year-old male patient presented with worsening epigastric pain since three days ago came to a nearby clinic. The pain had appeared for 4 months but had gotten worse in the last 3 days. It was described as heartburn that appears intermittently. Nausea, vomiting, and decreased appetite were reported. The patient took antacids to alleviate his symptoms, but they did not get better. He did not have a history of consumption of over-the-counter medications. The patient's vital signs were within the normal range.

The doctor diagnosed the patient with dyspepsia and suspected it is caused by $H$. pylori infection due to its high prevalence in the area. However, the UBT to confirm the infection is not available in the city, and the nearest hospital is $12 \mathrm{~h}$ away. The doctor had read an alternative to diagnose $H$. pylori infection by detecting its antigen in stool, considered doing a SAT on the patient rather than referring the patient. Nevertheless, the doctor wondered if SAT performance in diagnosing $H$. pylori infection was comparable to the UBT.

\section{Methods}

\section{Search strategy}

We searched for studies from five databases (PubMed, Cochrane, Scopus, EBSCO, and Proquest) using keywords: Dyspepsia, SAT, UBT, H pylori infection, and their synonyms, respectively. The keywords used on each search at different databases are shown in Table 1.

\section{Eligibility criteria}

The studies were determined to be eligible for this review using inclusion and exclusion criteria. The inclusion criteria cover the type of the study (systematic review/meta-analysis of cross-sectional study or cross-sectional study) and the relevance of the research which includes: (1) The SAT used in the study is immunoassay (EIA) and (2) the reference test used in the study is the UBT. As for the exclusion criteria, we excluded studies with animals, studies with
Table 1: Search strategy and keywords used

\begin{tabular}{|c|c|c|c|}
\hline \multirow{2}{*}{$\frac{\text { Database }}{\text { PubMed }}$} & Search terms & Hits articles & Selected articles \\
\hline & $\begin{array}{l}((((((\text { dyspepsia[Title/Abstract])) } \\
\text { OR (dyspeptic[Title/Abstract])) OR } \\
\text { (indigestion[Title/Abstract])) OR } \\
\text { (dyspepsia[MeSH Terms])) OR } \\
\text { (indigestion[MeSH Terms])) AND ((((((stool } \\
\text { antigen examination[Title/Abstract]) OR (stool } \\
\text { antigen test[Title/Abstract])) OR (fecal antigen } \\
\text { examination[Title/Abstract])) OR (fecal antigen } \\
\text { test[Title/Abstract])) OR (stool antigen[Title/ } \\
\text { Abstract])) OR (fecal antigen[Title/Abstract]))) } \\
\text { AND ((urea breath test) OR (UBT))) AND } \\
((((\text { helicobacter pylori[MeSH Terms]) OR } \\
\text { (helicobacter pylori infection[Title/Abstract])) } \\
\text { OR (h. pylori[Title/Abstract])) OR (h. pylori } \\
\text { infection[Title/Abstract])) }\end{array}$ & 73 & 2 \\
\hline Cochrane & $\begin{array}{l}\text { (dyspepsia OR dyspeptic OR indigestion) in } \\
\text { Title Abstract Keyword AND (stool antigen } \\
\text { examination OR fecal antigen examination } \\
\text { OR stool antigen OR fecal antigen OR } \\
\text { stool antigen test OR fecal antigen test) in } \\
\text { Title Abstract Keyword AND (urea breath } \\
\text { test OR UBT) in Title Abstract Keyword } \\
\text { AND (helicobacter pylori OR h pylori OR } \\
\text { helicobacter pylori infection) in Title Abstract } \\
\text { Keyword- (Word variations have been } \\
\text { searched) }\end{array}$ & 19 & 0 \\
\hline Scopus & $\begin{array}{l}\text { TITLE-ABS-KEY (dyspepsia OR dyspeptic } \\
\text { OR indigestion) AND (stool AND antigen } \\
\text { AND examination OR fecal AND antigen AND } \\
\text { examination OR stool AND antigen AND test } \\
\text { OR fecal AND antigen AND test OR stool } \\
\text { AND antigen OR fecal AND antigen) AND (ure } \\
\text { AND breath AND test OR ubt) AND ( } h \text {. pylori } \\
\text { OR } h \text {. pylori AND infection OR helicobacter } \\
\text { AND pylori OR helicobacter AND pylori AND } \\
\text { infection) }\end{array}$ & 100 & 1 \\
\hline EBSCO & $\begin{array}{l}\text { (TI Urea Breath Test OR TI UBT OR AB Urea } \\
\text { Breath Test OR AB UBT) AND (TI H. pylori } \\
\text { OR TI H. pylori infection OR TI helicobacter } \\
\text { pylori OR TI helicobacter pylori infection OR } \\
\text { AB H. pylori OR AB H. pylori infection OR AB } \\
\text { helicobacter pylori OR AB helicobacter pylori } \\
\text { infection) AND (TI stool antigen examination OR } \\
\text { TI fecal antigen examination OR TI stool antigen } \\
\text { OR TI fecal antigen OR TI stool antigen test } \\
\text { OR TI fecal antigen test OR AB stool antigen } \\
\text { examination OR AB fecal antigen examination } \\
\text { OR AB stool antigen OR AB fecal antigen OR } \\
\text { AB stool antigen test OR AB fecal antigen } \\
\text { test) AND (TI Dyspepsia OR TI Indisgestion } \\
\text { OR TI Dyspeptic OR AB Dyspepsia OR AB } \\
\text { Indisgestion OR AB Dyspeptic) }\end{array}$ & 33 & 0 \\
\hline Proquest & 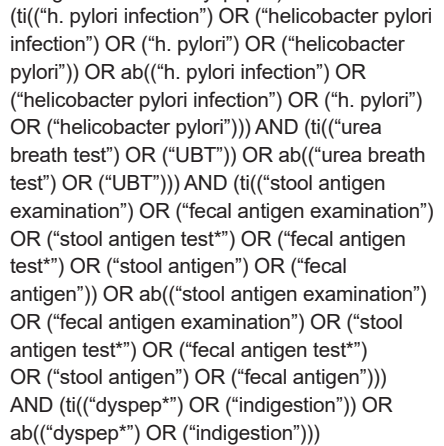 & 121 & 0 \\
\hline
\end{tabular}

a language other than English, and studies with no full text available.

\section{Critical appraisal}

The selected studies were appraised critically using the combination of Critical Appraisal Tools for Diagnostic Studies checklist from http://www.cebm.net (Oxford University). 


\section{Data extraction}

The data extracted from each study included validity (evidence level, blinding, the spectrum of patients, and reference standard), importance (sensitivity, specificity, positive predictive value, and negative predictive value), and applicability of the study in our setting.

\section{RESULTS}

\section{Search selection}

Articles on five different journal databases were performed using search terms provided in Table 1. These comprehensive searches were done to find articles regarding the SAT as a diagnostic tool for $H$. pylori infection compared to UBT. Then, articles obtained were screened using predefined selection and eligibility criteria.

Figure 1 shows the search and selection flow of studies selected in this EBCR. The study was carried out on five databases. After removing duplication articles between databases, 187 articles were obtained with the following details: 72 articles from PubMed, ten articles from Cochrane, 85 articles from Scopus, 12 articles from EBSCO, and 8 articles from Proquest. A hundred eightyseven articles were obtained, and then screened for titles and abstracts using eligibility criteria, and 18 articles met the criteria. After assessing 18 full-text articles using eligibility criteria, three studies were obtained (Hooton et al. [14], Chen et al. [15], and Braden et al. [16]). Subsequently, we appraised the three studies for their validity, importance, applicability, and level of evidence (Table 2)

\section{Discussion}

Validity tests were done in all three studies, and we concluded that all three articles were valid. In

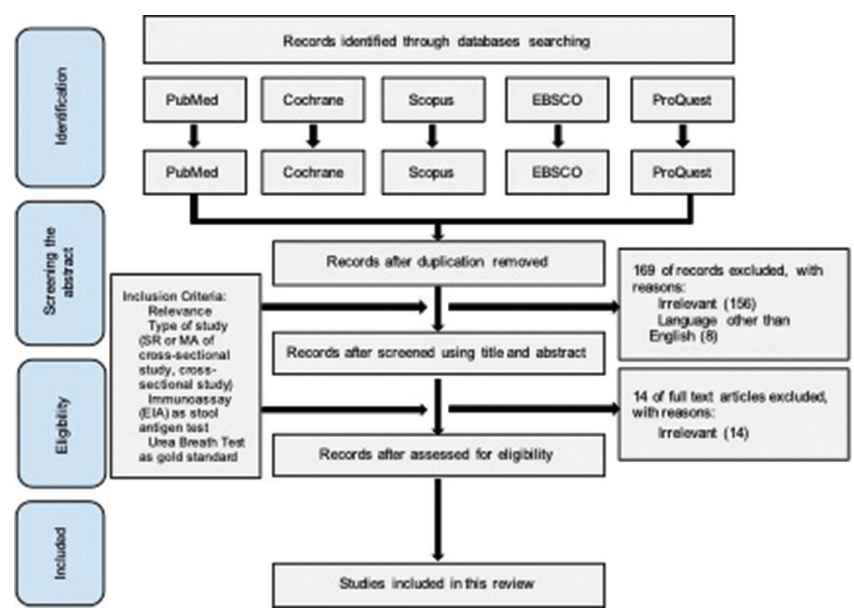

Figure 1: Flowchart of the searching strategy and study selection

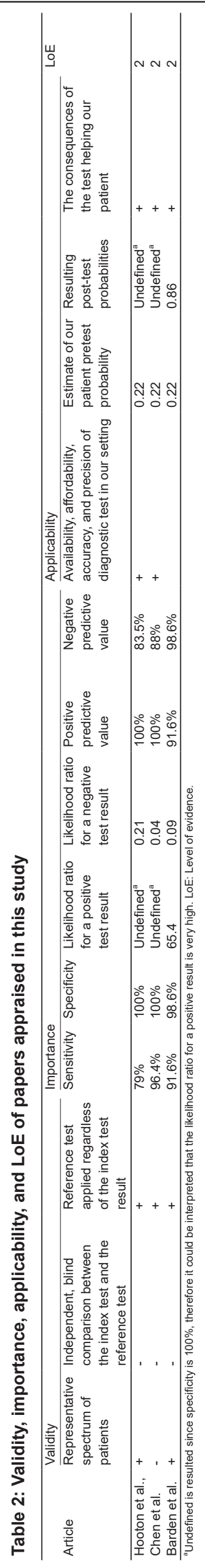


the study conducted by Hooton et al., the spectrum of patients is representative of those in whom it would be used in practice, including patients with dyspepsia. In the study, both the UBT and the SAT were done to every patient who was included in the trial, so the reference standard (in this case, UBT) was applied regardless of the index test result (SAT). However, blinding to the comparison of the UBT and SAT was not stated in the study [14]. In the second study done by Chen et al., the spectrum of patients included both patients with dyspepsia and asymptomatic patients. However, since the data analysis of patients with dyspepsia and asymptomatic patients is separated, it is still representative of those in whom it would be used in practice. In this study, every patient was tested with serology, UBT, HpSA ELISA test, and HpSA rapid test. Blinding to the comparison of these tests was not stated in the study [15]. In the study by Braden et al., the spectrum of patients included patients with abdominal pain, which is representative of those in whom it would be used in practice since one of the main signs of dyspepsia is abdominal pain. All patients were screened for $H$. pylori infection using the UBT and HpSA, so the reference standard test was used regardless of the index test result. The author also did not state the blinding to the comparison of both tests [16]. Although all three studies do not indicate the blinding to the comparison between the reference standard and the index test, the result of both tests (UBT and SAT) that were used is objective, so the chance of bias is low, therefore blinding to the comparison of these two tests is not necessary [14], [15], [16].

The sensitivity of the stool antigen examination presented in the three studies ranged from $79 \%$ to $96.4 \%$. The results indicate that the studies have high sensitivity, so SATs can help doctors rule out $H$. pylori infection. The three studies also demonstrate the remarkable specificity of stool antigen examination, ranging from $98.6 \%$ to $100 \%$. These results suggested that the SAT can help doctors in ruling in $H$. pylori infection (especially in the first two studies, the specificity is similar to the gold standard). For positive Likelihood Ratio (LR), Hooton et al. and Chen et al. have undefined results; meanwhile, Braden et al. has 65.4. Still, all of the studies show us a robust probability to find positive results in positive patients than in negative patients. In Hooton et al., Chen et al., and Braden et al.'s, the negative LR is $0.21,0.04$, and 0.085 , respectively. Although Hooton et al.'s result showed the probability of around $-30 \%$, studies done by Chen et al. and Braden et al. give us a strong probability to find negative results in negative patients than in positive $H$. pylori-infected patients due to the low score, which are lower than 0.1 . Positive predictive value in each Hooton et al., Chen et al., and Braden et al.'s studies is $100 \%, 100 \%$, and $91.6 \%$, respectively. The results are incredibly high, which means that there is a high probability for patients with positive results to be infected by $H$. pylori. Besides, negative predictive value for Hooton et al. is $83.5 \%$, for Chen et al. is $88 \%$, and for Braden et al. is $98.6 \%$. Although not as high as the positive predictive value, these scores are high enough to increase physician's confidence that negative patients are not infected by $H$. pylori. From these importance measurements, we can conclude that EIA SAT is as useful as UBT (almost have perfect scores) to be tools for ruling in the diagnosis of $H$. pylori infection, and is sufficient enough to be tools for ruling out the diagnosis of $H$. pylori infection aside from UBT test as the gold standard [17], [18].

Therefore, the application of the SAT as a choice in diagnosing $H$. pylori infection is reasonable. The SAT, in this case, the EIA, is widely available in Indonesia and inexpensive compared to UBT. Moreover, the SAT is found to be high in sensitivity and specificity. Furthermore, based on its LR, the SAT would generate moderate to significant changes to the pretest probability, which in turn would play a role in the doctor's decision to initiate treatment - in our setting, the pretest probability, solely determined by the prevalence of $H$. pylori infection in Indonesia, which is 0.22 [10], [19]. In respect of that, the post-test probability would be above 0.86 , which is relatively high. In conclusion, the SAT would help manage patients suspected of infection by $H$. pylori.

\section{Conclusion}

We conclude that SAT accuracy on diagnosing dyspeptic patients caused by $H$. pylori is comparable to UBT. Moreover, the SAT is more widely available and inexpensive than UBT.

\section{Authors contribution}

HML, JG, NT, NAT, and TR contribute in article collection, writing, and critical appraisal. ML involved in expert opinion, writing, and manuscript finalization.

\section{References}

1. Koduru P, Irani M, Quigley EM. Definition, pathogenesis, and management of that cursed dyspepsia. Clin Gastroenterol Hepatol. 2018;16(4):467-79. https://doi.org/10.1016/j. cgh.2017.09.002 PMid:28899670

2. Ozen A, Furman A, Berber M, Karatepe HO, Mutlu N, Sarıçoban HE, et al. The effect of Helicobacter pylori and economic status on growth parameters and leptin, ghrelin, and insulin-like growth factor (IGF)-I concentrations in 
children. Helicobacter. 2011;16(1):55-65. https://doi. org/10.1111/j.1523-5378.2010.00814.x

PMid:21241414

3. Thankachan P, Muthayya S, Sierksma A, Eilander A, Thomas T, Duchateau GS, et al. Helicobacter pylori infection does not influence the efficacy of iron and Vitamin B12 fortification in marginally nourished Indian children. Eur $\mathrm{J}$ Clin Nutr. 2010;64(10):1101-7. https://doi.org/10.1038/ejen.2010.126 PMid:20683455

4. Cherian S, Burgner DP, Cook AG, Sanfilippo FM, Forbes DA. Associations between Helicobacter pylori infection, co-morbid infections, gastrointestinal symptoms, and circulating cytokines in African children. Helicobacter. 2010;15(2):88-97. https://doi. org/10.1111/j.1523-5378.2009.00740.x

PMid:20402811

5. Abdollahi A, Morteza A, Khalilzadeh O, Zandieh A Asgarshirazi M. The role of Helicobacter pylori infection in gastro-oesophageal reflux in Iranian children. Ann Trop Paediatr. 2011;31(1):53-7. https://doi.org/10.1179/14653281 10y.0000000004

PMid:21262110

6. Tanih NF, Okeleye BI, Ndip LM, Clarke AM, Naidoo N Mkwetshana N, et al. Helicobacter pylori prevalence in dyspeptic patients in the Eastern Cape Province race and disease status. S Afr Med J. 2010;100(11):734-7. https://doi.org/10.7196/samj.4041 PMid:21081026

7. Joutei HA, Hilali A, Fechtali T, Rhallabi N, Benomar H. Helicobacter pylori infection in 755 patients with digestive complaints: Pasteur Institute, Morocco, 1998-2007. East Mediterr Health J. 2010;16(7):778-82. https://doi. org/10.26719/2010.16.7.778

8. Hestvik E, Tylleskar T, Kaddu-Mulindwa DH, Ndeezi G, Grahnquist L, Olafsdottir E, et al. Helicobacter pylori in apparently healthy children aged 0-12 years in urban Kampala, Uganda: A community-based cross-sectional survey. BMC Gastroenterol. 2010;10(1):62. https://doi.org/10.1186/1471-230x-10-62

9. Epplein M, Signorello LB, Zheng W, Peek RM, Michel A, Williams SM, et al. Race, African ancestry, and Helicobacter pylori infection in a low-income United States POpulation. Cancer Epidemiol Biomarkers Prev. 2011;20(5):826-34. https:// doi.org/10.1158/1055-9965.epi-10-1258

PMid:21357376

10. Syam AF, Miftahussurur M, Makmun D, Nusi IA, Zain LH, Zulkhairi, et al. Risk factors and prevalence of Helicobacter pylori in five largest Islands of Indonesia: A preliminary study. PLoS One. 2015;10(11):e0140186. https://doi.org/10.1371/journal.

\section{pone.0140186}

PMid:26599790

11. Syam AF, Simadibrata M, Makmun D, Abdullah M, Fauzi A, Renaldi $\mathrm{K}$, et al. National consensus on management of dyspepsia and Helicobacter pylori infection. Acta Med Indones. 2017;49(3):279-87

PMid:29093241

12. Ferwana M. Accuracy of urea breath test in Helicobacter pylor infection: Meta-analysis. World J Gastroenterol. 2015;21(4):1305-14. https://doi.org/10.3748/wjg.v21.i4.1305 PMid:25632206

13. Miftahussurur M. Noninvasive Helicobacter pylori diagnostic methods in Indonesia. Gut Liver. 2020;14(5):553-9. https://doi. org/10.5009/gnl19264

PMid:31693853

14. Hooton C, Keohane J, Clair J, Azam M. O'Mahony S Crosbie $\mathrm{O}$, et al. comparison of three stol antigen assays with the ${ }^{13} \mathrm{C}$-urea breath test for the primary diagnosis of Helicobacter pylori infection and monitoring treatment outcome. Eur J Gastroenterol Hepatol. 2006;18(6):595-9. https://doi. org/10.1097/00042737-200606000-00004

PMid:16702847

15. Chen MJ, Fang YJ, Wu MS, Chen CC, Chen YN. Application of Helicobacter pylori stool antigen test to survey the updated prevalence of Helicobacter pylori infection in Taiwan. J Gastroenterol Hepatol. 2020;35(2):233-40. https://doi. org/10.1111/jgh.14828

PMid:31408909

16. Braden B, Posselt HG, Ahrens P, Kitz R, Dietrich CF, Caspary WF. New immunoassay in stool provides an accurate non-invasive diagnostic method for Helicobacter pylori screening in children. Pediatrics. 2000;106:115-7. https://doi.org/10.1016/ s0016-5085(00)84138-4

PMid:10878159

17. Chey WD, Wong BC. American college of gastroenterology guideline on the management of Helicobacter pylori infection. Am J Gastroenterol. 2007;102(8):1808-25.

PMid:17608775

18. Avisiena A, Nusi IA, Maimunah U, Rahaju AS, Setiawan PB, Purbayu $\mathrm{H}$, et al. Diagnostic values of Helicobacter pylori stool antigen immunochromatographic method compared to histopatholgy in dyspepsia patient. New Armen Med J. 2019;3(1):13-9.

19. Syam AF. Current situation of Helicobacter pylori infection in Indonesia. Med J Indones. 2016;25(4):263-6. 